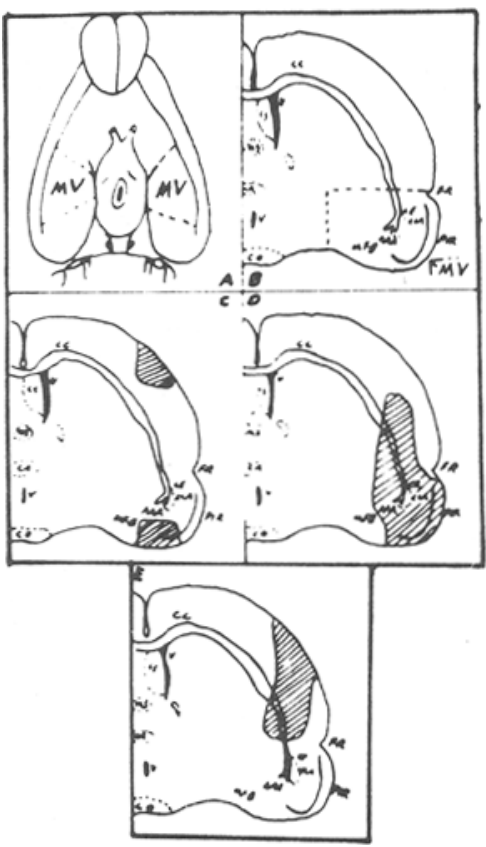

Fig. 1. A and B. The MV tissue of previous experiments is circumscribed by the dotted lines. C. The MD and $M V$ lesions in Experiment 1. D. The lesion area in Experiment 2. E. The lesion in Experiment 3. AAA-Area Amygdaloidea Anterior; CA-Commissura Anterior; $\mathrm{CC}$ Corpus Callosum; CE-Capsula Externa; CLA-Claustrum; CO-Chiasma Opticum; FR-Fissura Rhinalis; $\mathbf{L}$-Nucleus Lateralis Septi; MFB-Fasciculus Medialis Telen cephalia (medial forebrain bundle); MSNucleus Medialis Septi; PIR-Cortex Piriformis; V-Ventriculus Cerebri.

end of the electrode was free from insulation for a height of $.010 \mathrm{in}$. The current was set at $2 \mathrm{~mA}$ for $20 \mathrm{sec}$. Coordinates were the same anteriorly and laterally as in Experiment 2 , but the dorsal-ventral coordinates for this lesion was set $5.6 \mathrm{~mm}$ above EBZ.

Twelve pairs of littermate rats similar to those in Experiment 2 were used. Because of deaths and experimental rejections, analysis according to pairing had to be discarded. The final analy sis was based on eight rats in each group. Each animal's behavior was evaluated first in a shock-avoidance task. Supplementary information was obtained later concerning the performance of each animal in a six-unit water $T$ maze. Each rat was given five training trials; the number of trials completed within $30 \mathrm{sec}$ in 10 test trials was the dependent variable as in previous work (Gaito. Davison, \& Mottin. 1969).

Table 1 shows the data for the shockavoidance conditioning and water-maze task. In neither case were the lesioned animals significantly different from the sham rats using a simple randumized ANOVA design

\section{DISCUSSION}

In Experiment 1 rats lesioned in the MV or MD brain areas were not significantly different from nonlesioned animals in conditioning behavior. The extent of the lesion was small and when the lesion in MV was increased in Experiment 2, the lesioned animals were inferior in performance. However, since the lesion in this latter experiment permeated the dorsal cortex as well as MV, the difference could be attributed to the dorsal lesion. Thus in Experiment 3 a lesion was inflicted in this portion of the dorsal cortex (DC) to evaluate this possibility. No significant differences were observed in shock-avoidance conditioning nor in learning a water-maze pattern. The results of the three experiments, when considered with the previous neurochemical work in this laboratory, suggest that MV tissue (which includes cortical and suboortical tissue) is involved in some manner in shock-avoidance conditioning, and possibly in water-naze learning. Considering that the lesions impinged upon the amygdala and this structure has been implicated as having an important role in fear regulation (Goddard, 1964), it is reasonable to speculate that these and the previous results may reflect amygdala activity since some stress is involved in both shock-avoidance conditioning and in water-maze performance. More experimentation is required to provide further information concerning the involvement of the MV area in learning behavior.

\section{REFERENCES}

De GROOT, J. The rat brain in stereotaxic coordinates. Verhandelingen Der Koninklijke Nederlandse Akademie Van Watenschappen. Afd. Natuurkunde, 1959,52,1-40.

GAITO, J., DAVISON, J. H., \& MOTTIN, J. Chemical variation in brain loci during water maze performance. Psychonomic Science. $1969,14,46-48$.

GaITo, J., MOTTIN, J., \& DAVISON, J. H Chemical variation in the ventral hippocampus and other brain sites during conditioned avoidance. Psychonomic Science, 1968, 13, 259-260.

GODDARD, G. V. Functions of the anygdala.

Psy chological Bulletin. 1964, 62, 89-109. NOTE

1. This research was supported by Office of Naval Research Contract Nonr-4935(00) and grants from the National Research Council of Canada.

\title{
Predatory behavior in two strains of laboratory mice
}

\section{KARLA THOMAS, - San Fernando Valley \\ State College, Northridge, Calif. 91324}

Eighteen C57BL/Crgl and $12 \mathrm{Is} / \mathrm{Bi} / \mathrm{Crgl}$ male mice, not deprived of food, attacked and ate crickets on two occasions. In comparison with Is, C57BL mice had longer attack latencies on both trials, spent their initial minutes in mure approachwithdrawal behavior, and showed a significant decrease in attack latency on Trial 2. Cricket-killing behavior mav be related to fighting behavior in the mouse.

Although the house mouse, Mus musculus, is an omnivorous rodent, the literature contains little information concerning its predatory behavior. Casual observation of the killing and eating of a house cricket by an adult male $\mathrm{C} 57 \mathrm{BL} / \mathrm{Crgl}$ mouse led to the experiment reported below. The experiment was designed to determine whether such predatory behavior is typical of male laboratory mice. The two inbred strains used differed in pigmentation and were derived originally from different laboratory stocks. Thus, similarities in their behavior may resemble the behavior of the wild mouse if reared under similar conditions.

\section{SUBJECTS}

The Ss were $18 \quad \mathrm{C} 57 \mathrm{BL} / \mathrm{Crgl}$ and 12 Is/Bi/Crgl male mice, all approximately 3 months old. All were purchased from the Cancer Research Genetics Laboratory, University of California, Berkeley. They were housed individually for at least? weeks before testing, and had a standard diet (Purina rodent chow) and water available ad lib. Each had been litter-reared and, prior to the present study. each had been used in an experiment on the effects of population size and density on fight initiation. However, no mouse was a trained fighter and none had previous experience with crickets.

APPARATUS AND PROCEDURE

Each mouse was given two opportunities to catch a cricket: these trials were separated by at least 3 days. A time limit of $30 \mathrm{~min}$ was imposed for each trial. The crickets, Acheta domesticus. Were active and of approximately equal size.

On each trial the mousc was weighed and replaced in its home cage, which was moved to an observation table. The food and water were removed and the cage top was replaced with a clean wire top. After a 
Table 1

I. ht ites (bog sec) th Mtack and to Eat Crickets: Freyuency Distributions of 18 C57BI. and 12 is Mice

\begin{tabular}{|c|c|c|c|c|c|c|c|c|}
\hline \multirow{2}{*}{$\frac{1+1, n \cdot y}{16 x}$} & \multicolumn{4}{|c|}{ Cilket 1} & \multicolumn{4}{|c|}{ Cricket 2 Cricket 2} \\
\hline & C57 & & $I^{s}$ & & C.57 & & $1^{\mathbf{S}}$ & \\
\hline 501 & Atk & Eat & Atk & Eat & Atk & Eat & Atk & Eat \\
\hline $0.40-0.79$ & 0 & 0 & 2 & 0 & 0 & 0 & 6 & 0 \\
\hline $0.80-1.19$ & 1 & 0 & 1 & 0 & 0 & 0 & 2 & 3 \\
\hline $1.20-1.59$ & 0 & 0 & 3 & 4 & 2 & 0 & 3 & 6 \\
\hline $1.60-1.99$ & 0 & 1 & 2 & 4 & 8 & 4 & 0 & 2 \\
\hline 2.002 .39 & 4 & 2 & 4 & 4 & 3 & 8 & 1 & 1 \\
\hline $2.40-2.79$ & 5 & 5 & 0 & 0 & 3 & 3 & 0 & 0 \\
\hline $2.80-3.19$ & 4 & 6 & 0 & 0 & 2 & 3 & 0 & 0 \\
\hline Maximun & II 4 & 4 & 0 & 0 & 0 & 0 & 0 & 0 \\
\hline
\end{tabular}

5-min adaptation period, and at a time when the mouse was in its nest, a cricket was introduced into the end of the cage opposite the mouse's nesting area. The following mouse behaviors were recorded on an Esterline-Angus pen recorder: ${ }^{3}$ grooming, burrowing through bedding material, attention posture (Grant \& Mackintosh, 1963), running to the nest, "searching" (sniffing the floor of the cage), chasing the cricket, attacking the cricket, killing the cricket, and eating some part of the cricket.

Occasionally a cricket would hop to the top of the cage. When this happened, E prodded it back to the cage floor with the sharp point of a pencil.

Several days after completion of the cricket-killing trials, the Ss and 24 others of the same strains were housed in groups of six, within strains. The resulting five groups of C57BL males and four groups of Is males were observed until fighting occurred or $30 \mathrm{~min}$ had passed.

\section{RESULTS}

of the categories used, "killing" was the most difficult to determine. The best measures for comparison of the two strains were latencies to first attack and to first eating of some part of the cricket. These were the only reliable categories common to all Ss; that is, all mice at some time attacked and ate a cricket, but not all mice displayed the other behaviors. For example, some $\mathrm{C} 57 \mathrm{BL}$, but no Is, animals groomed or burrowed through bedding material.
The results are shown in Table 1 . It is obvious that $I^{\mathbf{s}}$ mice capture and eat crickets more quickly than do $\mathrm{C} 57 \mathrm{BL}$ mice. Separate Mann-Whitney U tests comparing the strains on each trial showed significant differences $(p<.0001$ for each trial). In subjective terms, the $I^{s}$ strain was bold and efficient in its attack, while the C57BL engaged in much approachwithdrawal behavior before attacking. The strain difference can be seen in Table 2 by comparison of the categories "attention" and "run to nest" with the categories of attacking and eating. While the $I^{s}$ mice spent their first $2 \mathrm{~min}$ in direct pursuit of the crickets, the C57BL mice vacillated between approach and withdrawal (defined as the attention posture followed by a return to the nest).

For the two strains combined there was a decrease in attack latency from Trial 1 to Trial 2 ( $\mathrm{p}<.001$, sign test). When analyzed separately, only the $\mathrm{C} 57 \mathrm{BL}$ strain showed a significant decrease $(p<.003)$. Presumably the $I^{s}$ animals were limited by a ceiling; they performed so well on Trial 1 that relatively little improvement was possible on Trial 2.

When the mice were placed in group cages at the end of the experiment, a strain difference was again noticed. The $\mathbf{I}^{\mathrm{s}}$ mice fought with each other sooner than did the C57BL mice $(p=.008$, exact probability). During the fights, the $I^{s}$ mice drew blood and squeaked, while the C57BL mice did not. Thus, in these strains, the more efficient predator was also the more aggressive with respect to fighting.

Table 2

Behavior of $\mathrm{C} 57 \mathrm{BL}$ and $\mathrm{I}^{\mathrm{s}}$ Mice during First $2 \mathrm{~min}$ of Trial 1

\begin{tabular}{|c|c|c|c|c|}
\hline \multirow{2}{*}{$\begin{array}{l}\text { Behavior } \\
\text { Category }\end{array}$} & \multicolumn{2}{|c|}{ C57BL $(N=12)^{3}$} & \multicolumn{2}{|c|}{$I^{S} \quad(N=12)$} \\
\hline & Mdn & Range & Mdn & Range \\
\hline Attention (f) & 6 & $1-15$ & 2 & 0.4 \\
\hline Run to Nest (f) & 6.5 & $0-12$ & 0 & $0-2$ \\
\hline "Searching" (sec) & 4.5 & $0-59$ & 16.5 & $0-70$ \\
\hline Chasing (sec) & 0.5 & $0-10$ & 4 & $1-18$ \\
\hline Attacking (sec) & 0 & $0-38$ & 21 & $0-39$ \\
\hline Lating (sec) & 0 & $0-43$ & 34 & $0-86$ \\
\hline
\end{tabular}

$f=$ frequency of behavior; $\sec =$ total sec of behavior

\section{D)ISCLISSION}

The strain difference in cricket-killing secms to reside in the bethavior of the mice hetore catching a cricket rather than in the ittack pattern itself. Though detailed analysis of the attack pattern was not pussible with the observation technique used here, both strains seemed to attack in the same manner, by biting the crickets to death. Both ate the crickets completely, but did not appear to eat any specific part first. The strain difference in time required during the first and second trials suggests that while Is mice are "good" predators on the first trial, $\mathrm{C} 57 \mathrm{BL}$ mice require experience in order to become efficient at predation. If allowed to establish themselves under natural conditions, C57BL mice might never catch crickets; uncaged crickets could escape from them easily. However, if predation and intraspecies aggression are based on some common mechanisms, it is possible that cricketkilling could be facilitated by prior experience in fighting other mice or in establishing social dominance among littermates. The $I^{s}$ mice, the more efficient predators and the more aggressive in group cages, may well have had more fighting experience than the C57BL before arriving in this laboratory. Further tests are necessary in order to determine the extent to which prior experience is involved in the predatory behavior of laboratory mice.

Insect-killing is a behavior which probably occurs among wild house mice. Crickets and other insects could provide a valuable source of protein, and the behavior of apparently well-fed laboratory mice toward crickets warrants investigation of a possible deficiency in the usual standard diets of laboratory mice.

As a measure of attack behavior, the cricket-killing response is easy to obtain in the laboratory, and as a behavior amenable to genetic analysis, cricket-killing may be , useful because it may occur under natural selection

\section{RI:PERENCE}

GRANT, E. C., \& MACKINTOSH, J. H. A comparison of the social postures of some common laboratory rodents. Behaviour, 1963, $21,246-259$.

\section{NOTES}

1. This research was supported in part by a College Institutional Science Grant awarded by the faculty of San Fernando Valley State College. I thank Dr. Jim Dole and Dr. Roy Griffiths for supplying crickets, and Dr. William Wilsoncroft for calling attention to the initial encounter betwcen mouse and cricket.

2. Address until June, 1969: Institute of Human Development. University of California, Berkeley, California 94720.

3. The pen recorder was not used for the first six C.57BL animals. Their latency measures were obtained with a stopwatel. 